\title{
Characterization of Lactobacilli Isolated From Four Different Sources
}

\author{
Ligimol James*¹, Beena A K, Sreeshma N \\ Department of Dairy Microbiology, College of Dairy Science and Technology, Mannuthy, Thrissur
}

\begin{abstract}
Lactobacilli, the Gram positive, non spore forming, catalase negative rod shaped lactic acid bacteria are used widely as starter cultures for food fermentations and also as probiotic cultures due to their functional attributes. In this study, four lactobacilli each isolated from different sources namely: carrot, idli batter, dahi and duck feces were assessed for various attributes like antimicrobial, bile salt hydrolysis, proteolytic and lecithinase activities and their ability to grow at different salt concentrations. All the isolates were able to grow in salt concentrations as high as five percent and possessed bile salt hydrolase, an enzyme that imparts bile salt tolerance. All of them were also found to be antagonistic against S. aureus with the isolate from carrot giving the largest zone of inhibition of $16 \mathrm{~mm}$ diameter. Two of the isolates were found to be moderately proteolytic and none of the isolates showed lecithinase activity.
\end{abstract}

Key words: Antimicrobial activity, Bile salt hydrolysis, Lactobacilli, Proteolytic activity, Salt tolerance

\section{Introduction}

Lactic acid bacteria (LAB) are a group of Gram positive bacteria having a long history of safe use in the food industry. They are acid tolerant, microaerophilic, non sporulating rods or cocci that ferment lactose producing lactic acid. The genus of lactic acid bacteria that is most commonly used in food fermentations is Lactobacillus [1]. They are widely being used as starter cultures in the preparation of a number of fermented dairy, vegetable and meat products. Members of this genus are also well acclaimed for their probiotic attributes. Considering the functional and technological significance of Lactobacilli there is always a thrust towards isolating new strains of Lactobacilli and functionally characterizing them. Owing to their unique potential for adaptation, lactobacilli are often encountered in a wide range of different environmental niches. As there could be habitat specific variations in the metabolic profile and starter culture potential of lactobacilli, natural habitats are often considered as potential sources to obtain prospective strains for food industry. Considering these facts an attempt was done to characterize lactobacilli isolated from four entirely different niches namely: carrot, idli batter, dahi and duck feces.

\subsection{Lactobacilli isolates}

\section{Materials and Methods}

Four Lactobacillus cultures isolated from various sources (carrot, idli batter, dahi and duck feces) and maintained as glycerol stock in the culture collection of Department of Dairy Microbiology were used in the present study. The cultures were activated by growing in sterile deMan Rogosa Sharpe (MRS, Himedia, Mumbai) broth at $37^{\circ} \mathrm{C}$ for 48 hours. The activated cultures thus obtained were transferred to MRS agar slants and maintained at $4^{\circ} \mathrm{C}$ with fortnightly subculturing. Active cultures were subjected to Gram staining, catalase test and motility test (hanging drop method) [2]. Gram stained cultures were examined microscopically for the presence of Gram positive rods. The catalase test was performed by the slide method by mixing a small amount of the culture with one drop of 3\% hydrogen peroxide and observing for the development of effervescence. Motility of the isolates was tested by the hanging drop method. The ability of the isolates to ferment carbohydrates was determined by observing for color change and gas production upon inoculation and incubation of Andrade peptone water (Himedia, Mumbai) tubes containing the respective carbohydrate discs at $37^{\circ} \mathrm{C}$ for 7 days. The cultures were also assessed for their ability to grow at various temperatures $\left(37^{\circ} \mathrm{C}, 45^{\circ} \mathrm{C}\right.$ and $10^{\circ} \mathrm{C}$ ) by incubating the inoculated MRS broth tubes at these temperatures for 48 hours and visually observing for development of turbidity. The ability to grow at different $\mathrm{NaCl}$ concentrations $(1.5 \%, 3 \%$, and $5 \%$ ) was also tested in a same fashion.

\subsection{Activity testing of the isolates}

Antimicrobial activity of the isolates against $S$ aureus was determined by the agar well diffusion method [3]. Ability to produce the enzyme bile salt hydrolase was assessed qualitatively by streak culturing the isolates on MRS and Lactobacillus selection Oxgall agar (HiMedia, Mumbai) followed by incubation at $37^{\circ} \mathrm{C}$ for 48 hours. Development of a white precipitation solely in Oxgall agar was considered as a positive test [4]. 
The proteinase and lecithinase activies of the isolates were tested by streaking them on skim milk agar (Nutrient agar with 10\% skim milk ) and Egg Yolk Agar (Nutrient agar supplemented with 6\% egg yolk emulsion) respectively followed by incubation at $37^{\circ} \mathrm{C}$ for 48 hours [2] with some modifications. Development of zone of clearance around the colonies was considered as positive test for proteolytic activity and development of opaque (precipitation) zone around the colonies indicated the lecithinase production.

\section{Results and Discussion}

\subsection{Morphological and Biochemical characterization of isolates}

All the isolates formed small/ large, dry/smooth creamy white convex or sub- surface spindle shaped colonies on pour plating on MRS agar. Microscopic examination of Gram stained preparations of isolates revealed all the isolates as purple rods arranged singly or in clusters (Table 1). The isolates were also found to be non- motile on performing the hanging drop method. All the isolates failed to form any gas bubbles on treating with hydrogen peroxide indicating their catalase negative nature. Thus all the four isolates were found to be Gram positive, rod shaped non-motile, catalase negative bacteria.

Table1. Colony Morphology and Gram reaction of the isolates

\begin{tabular}{|c|c|c|c|c|}
\hline Isolates & Source of isolation & Colony morphology & Gram reaction & Microscopic appearance \\
\hline Isolate 1 & Carrot & $\begin{array}{l}\text { Small, creamy white, convex, } \\
\text { entire margin, sub-surface, dry } \\
\text { and spindle shaped colonies }\end{array}$ & Short, Gram positive rods & \\
\hline Isolate 2 & Idli batter & $\begin{array}{l}\text { Large, creamy white, convex, } \\
\text { entire margin, sub-surface, } \\
\text { smooth and spindle shaped } \\
\text { colonies }\end{array}$ & Short, Gram positive rods & \\
\hline Isolate 3 & Dahi & $\begin{array}{l}\text { Small, creamy white, convex, } \\
\text { entire margin, sub-surface, } \\
\text { smooth and spindle shaped } \\
\text { colonies }\end{array}$ & $\begin{array}{l}\text { Short single Gram positive } \\
\text { rods }\end{array}$ & \\
\hline Isolate 4 & Duck feces & $\begin{array}{l}\text { Large, creamy white, convex, } \\
\text { entire margin, sub-surface, dry } \\
\text { and spindle shaped colonies }\end{array}$ & Short, Gram positive rods & \\
\hline
\end{tabular}

\subsection{Sugar fermentation and growth at different temperatures and salt concentration}

Differences were observed among the isolates in their ability to ferment the sugars Arabinose, Galactose, Mannitol, Mellibiose, Raffinose and Xylose (Table 2). None of the isolates were capable of fermenting the sugar Rhamnose. Rest of the sugars namely, Cellobiose, Dextrose, Fructose, Lactose, Maltose, Mannose, Salicin and Sucrose were fermented by all the isolates. None of the isolates produced gas on fermenting Glucose/Dextrose indicating their homofermentative nature. On assessing the ability of the isolates to grow at different temperatures $\left(10^{\circ} \mathrm{C}, 37^{\circ} \mathrm{C}\right.$ and $\left.45^{\circ} \mathrm{C}\right)$, it was observed that all the four isolates could grow at $37^{\circ} \mathrm{C}$ (Table 2). Only two isolates (1 and 3) could grow at $10^{\circ} \mathrm{C}$. Lactobacillus isolated from duck feces alone could grow at $45^{\circ} \mathrm{C}$ exhibiting its thermophilic nature. It is being reported that $\mathrm{NaCl}$ concentration of more than $3 \%$ hampers the growth of $\operatorname{LAB}[5,6,7,8]$. Contrary to this report it was found that all the isolates used in the current study were able to grow even at $5 \% \mathrm{NaCl}$, the highest concentration tested. Isolation of Lactobacilli capable of growing at $\mathrm{NaCl}$ concentration as high as $18 \%$ is reported by other researchers [9, 10]. As salt tolerant lactic acid bacteria are of paramount importance in the ripening and flavor development of pickled cheeses like Domiati and in the pickling of vegetables like cucumber, cabbage and olives [11,12] the isolates could be of use in this direction. 
Table 2. Biochemical, Physiological and Antimicrobial characteristics of the isolates

\begin{tabular}{|c|c|c|c|c|c|}
\hline $\begin{array}{l}\text { SL } \\
\text { No. }\end{array}$ & Parameter & Isolate 1 & Isolate 2 & Isolate 3 & Isolate 4 \\
\hline 1. & Catalase & - & - & - & - \\
\hline 2. & Motility & - & - & - & - \\
\hline \multirow[t]{4}{*}{3.} & \multicolumn{5}{|c|}{ Growth at different temperatures } \\
\hline & $10^{\circ} \mathrm{C}$ & + & - & + & - \\
\hline & $37^{\circ} \mathrm{C}$ & + & + & + & + \\
\hline & $45^{\circ} \mathrm{C}$ & - & - & - & + \\
\hline \multirow[t]{4}{*}{4.} & \multicolumn{5}{|c|}{ Growth at different salt concentrations } \\
\hline & $1.5 \% \mathrm{NaCl}$ & + & + & + & + \\
\hline & $3 \% \mathrm{NaCl}$ & + & + & + & + \\
\hline & $5 \% \mathrm{NaCl}$ & + & + & + & + \\
\hline \multirow[t]{16}{*}{5} & \multicolumn{5}{|c|}{ Carbohydrate utilization } \\
\hline & Arabinose & & + & - & - \\
\hline & Cellobiose & + & + & + & + \\
\hline & Dextrose & + & + & + & + \\
\hline & Fructose & + & + & + & + \\
\hline & Galactose & - & + & + & + \\
\hline & Lactose & + & + & + & + \\
\hline & Maltose & + & + & + & + \\
\hline & Mannitol & + & + & + & - \\
\hline & Mannose & + & + & + & + \\
\hline & Melibiose & + & + & - & - \\
\hline & Raffinose & + & + & - & - \\
\hline & Rhamnose & - & - & - & - \\
\hline & Salicin & + & + & + & + \\
\hline & Sucrose & + & + & + & + \\
\hline & Xylose & - & + & + & + \\
\hline \multirow[t]{2}{*}{6} & \multicolumn{5}{|c|}{ Antimicrobial activity against $S$ aureus -Zone of clearance inclusive of disc diameter of $6 \mathrm{~mm}$ ) } \\
\hline & $16 \mathrm{~mm}$ & $13 \mathrm{~mm}$ & $14 \mathrm{~mm}$ & $13 \mathrm{~mm}$ & \\
\hline
\end{tabular}

\subsection{Antimicrobial activity of the isolates}

All the isolates showed antimicrobial activity against $S$. aureus (Table 2). Maximum inhibition was exhibited by isolate1, obtained from carrot giving a zone of inhibition of $16 \mathrm{~mm}$, followed by isolate 3 with a zone of clearance of $14 \mathrm{~mm}$. Classification of antimicrobial activity into moderate (6-9 mm), strong (10-14 $\mathrm{mm})$, and very strong $(15-18 \mathrm{~mm})$ categories based on zone of inhibition[13] was followed in this study. Based on this criterion, the antimicrobial activity exhibited by isolate 1 could be graded as very strong whereas all other isolates fit into the category of strong inhibition. Antimicrobial activity of lactobacilli strains against different organisms like E coli, S aureus, E. aerogenes has been reported by a number of researchers [13, 14, 15]. Lactic acid bacteria are found to produce a variety of antibacterial agents including organic acids, diacetyl, $\mathrm{H}_{2} \mathrm{O}_{2}$ and bacteriocins [16]. So the inhibition zone observed in this study could be due to the production of any of these agents and needs to be further investigated.

\subsection{Bile Salt Hydrolysis activity of the isolates}

All the isolates formed white colored colonies on oxgall agar indicating their bile salt hydrolase (BSH) activity (Fig. 1). Bile salt hydrolases catalyze deconjugation of conjugated bile salts into amino acid residues and bile acids. This deconjugation process is suggested as an important detoxification mechanism of microorganisms during colonization in the gastrointestinal tract [17, 18]. This process is also hypothesized as one of the indirect means to decrease cholesterol level in humans [19]. Contrary to the reports [20] that the lactic acid bacteria isolated from human intestine or feces are BSH positive and that of food-origin are mostly BSH negative, in the current study all the isolates regardless of their source of isolation exhibited BSH activity. As BSH activity is considered as a property of importance in lowering serum cholesterol levels [21, 22] all the isolates could be considered as potential candidates for their hypocholesteremic effect. Considering that marked differences are reported between the BSH activities of microorganisms derived from various sources [23] it is required to quantify $\mathrm{BSH}$ activities of the isolates to derive such a correlation. 


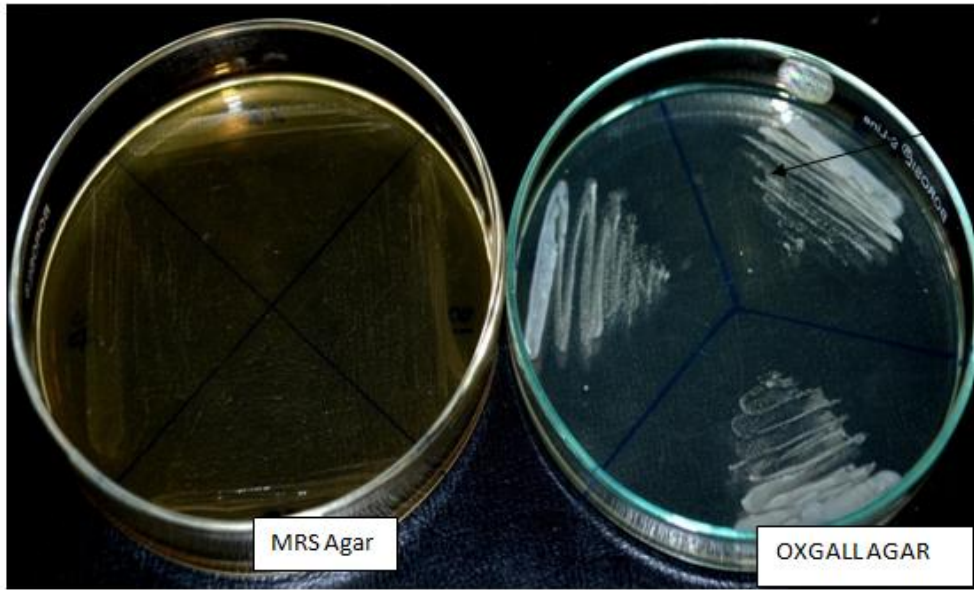

White precipitatio

Thdicating bile salt

hydrolase production

Figure1: Plate assay for bile salt hydrolase (BSH) activity in MRS agar and Oxgall agar

\subsection{Proteolytic activity of the isolates}

As LAB are fastidious in nature they have developed a complex proteolytic system of proteinases and peptidases to support their growth. Contrary to this general observation, only two isolates 1 and 4, isolated from carrot and duck feces respectively formed zone of clearance around the growth indicating their proteolytic activity. (Fig. 2) Considering the fact that most of the LAB isolated from fermented dairy products have multiple amino acids auxotrophy and their growth in protein rich medium depends on expression of a complex proteolytic system for the degradation of casein [24] it is interesting to note that isolate 3 obtained from dahi, a fermented milk product was unable to degrade the proteins provided by skim milk. The proteolytic activity is of special significance in cheese ripening. Further the range of bioactive peptides released by LAB depend on their proteolytic system. Proteolytic potential of lactobacilli isolated from different sources has been reported by other researchers also $[15,24,25]$.

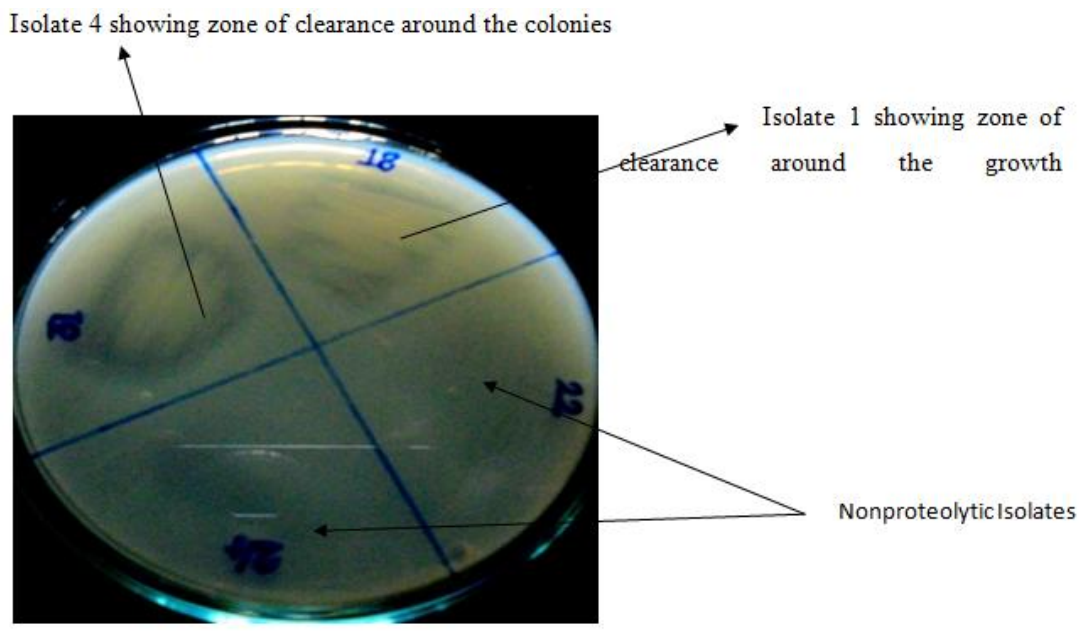

Figure 2: Skim milk plate with zone of clearance exhibiting proteolytic activities of isolates

\subsection{Lecithinase activity of the isolates}

In this study, none of the isolates produced lecithinase as there was no opaque (precipitation) zone around the colonies. Lecithinase (phospholipolytic) activity is used as an indicator of food toxicity [26]. Considering the fact that the LAB are widely being used in food fermentations it is essential to ensure that these organisms are safe for human consumption. So assessment of lecithinase activity could be considered as a selection criteria while screening microorganisms for use in food industry.

\section{Conclusion}

Lactobacilli are a group of microorganisms widely used for a number of industrial fermentation processes ranging from the preparation of fermented food products to production of biopolymer. They are also of special significance due to the functional properties attributed to it. In this context there is always a need to isolate them from different sources and screen for various industrial uses. In the present study, isolates from 
different sources were found to differ in their activities. Among the isolates, isolate 1, obtained from carrot showed highest antimicrobial activity against $S$ aureus. Exhibition of antimicrobial as well as proteolytic and bile salt hydrolysis activities by the same isolate proposes it as a potential candidate for further study on its probiotic and related properties for its efficient utilization as a functional Lactobacilli.

\section{References}

[1]. H. Pyar and , K.K. Peh., Characterisation and Identification of Lactobacillus acidophilus using Biolog Rapid Identification System. International Journal of Pharmacy and Pharmaceutical Sciences. 6(1), 2013, 189-193

[2]. W.F. Harrigan, Laboratory methods in food microbiology ( ${ }^{\text {rd }}$ Edition, Academic Press, 1998 )

[3]. T. R Tagg, A.S Dajani, and L. W. Wannamaker, Bacteriocin of Gram-positive bacteria. Bacteriological Reviews.40(3),1976, 722756.

[4]. Y.T.Ahn, G.B. Kim, K.S., Lim, Y.J. Baek, H.U. Kim , Deconjugation of bile salts by Lactobacillus acidophilus isolates. International Dairy Journal 13(4), 2003, 303-311.

[5]. H. Korkeala, T. Alanko, T.Tiusanen (1992) Effect of sodium nitrite and sodium chloride on growth of lactic acid bacteria. Acta Veterinaria Scandinavica 33(1), 1992, 27-32.

[6]. F.V Passos, H.P. Flemming, D.F. Ollis, H.M Hassan, and R.M Felder, Modeling the specific growth rate of Lactobacillus plantarum in cucumber extract. Applied Microbiology Biotechnology .40(1), 1993, 143-150.

[7]. M.G.Ga "nzle, , M. Ehrmann, and W.P. Hammes, Modeling of growth of Lactobacillus sanfranciscensis and Candida milleri in response to process parameters of sourdough fermentation. Applied and Environmental Microbiology, 64(7), 1998, 2616-2623.

[8]. S. Samapundo, J.Ampofo-Asiama, T.Anthierens, R. Xhaferi, I.Van Bree, S.Szczepaniak, O.Goemaere, L.Steen, M. Dhooge, H. Paelinck, K.Dewettinck and F. Devlieghere, Influence of $\mathrm{NaCl}$ reduction and replacement on the growth of Lactobacillus sakei in broth, cooked ham and white sauce. International Journal of Food Microbiology 143(1), 2010, 9-16.

[9]. D. Huang, Y.Q. Liu, Y.Liang and X. Mao, Isolation and screening of salt tolerance lactic acid bacteria strain and study on its characteristic producing lactic acid. Advanced Materials Research, 881-883, 2014, 746-750.

[10]. L. ZiMing, X Jing., J.LiWen and L. YunQian, Isolation and identification of salt-tolerance lactic acid bacteria from high-salt chilli. Journal of Food Safety and Quality, 5 (4), 2014, 1016-1020.

[11]. M . El-Gendy, H. Abdel-Galil, Y. Shaidn and F. Z Hegazi..Characteristics of Salt-tolerant Lactic Acid Bacteria, in Particular Lactobacilli, Leuconostocs and Pediococci, isolated from salted raw milk. Journal of Food Protection 46. (5), 1983, 429-433.

[12]. R. Di Cagno, R .Coda, M. De Angelis and M.Gobbetti, Exploitation of vegetables and fruits through lactic acid fermentation. Food Microbiology,33(1),2013, 1-10.http://dx.doi.org/10.1016/j.fm.2012.09.00

[13]. S. A., Liasi, T. I. Azmi, M. D.Hassan, M. Shuhaimi, M. Rosfarizan, and A. B. Ariff, Antimicrobial activity and antibiotic sensitivity of three isolates of lactic acid bacteria from fermented fish product, Budu. Malaysian Journal of Microbiology 5 (1), 2009, 33-37.

[14]. D .Hernandez, E .Cardell and V. Zarate, Antimicrobial activity of lactic acid bacteria isolated from Tenerife cheese: initial characterization of plantacin TF 711, a bacteriocin-like substance produced by Lactobacillus plantarum TF 711. Journal of Applied Microbiology, 99(1), 2005, $77-84$.

[15]. J.Atanasova, P. Moncheva, and I. Ivanova, Proteolytic and antimicrobial activity of lactic acid bacteria grown in goat milk. Biotechnology, Biotechnological Equipment,28(6),2014,1073-1078.

[16]. L. Topisirivic , M. Kojic, D. Fira, N. Goic, I. Strahinic and J. Lozo.Potential of lactic acid bacteria isolated from specific natural niches in food production and preservation. Inernational Journal of Food Microbiology, 112(3), 2006, 230-5.

[17]. P .Jarocki, M. Podlesny, P. Glibowski and Z Targonski, A New Insight into the Physiological Role of Bile Salt Hydrolase among Intestinal Bacteria from the Genus Bifidobacterium. PLoS One, 9(12), 2014,1-24.

[18]. P.Sedláčkov, S. Horáčková, T Shi, M. Kosová, and M Plocková,Two different methods for screening of bile salt hydrolase activity in Lactobacillus strains. Czech Journal of Food Sciences, 33 (1), 2015,13-18 .

[19]. M . Begeley, C. Hill, and C.G. Gahan ,Bile salt hydrolase activity in probiotics. Applied and Enviromental. Microbiology 72(1), 2006, 729-1738.

[20]. H .Tanaka, T .Doesburg, T .Iwasaki, and I .Mierau, Screening of lactic acid bacteria for bile salt hydrolase activity. Journal of Dairy Science, 82(12), 1999, 2530-2535

[21]. M .Du Toit, C.M. Franz, L.M. Dicks, U. Schillinger, P.Harberer, B.Warlies, , E. Ahrens, and W. H. Holzapfel , Characterization and selection of probiotic lactobacilli for a preliminary mini-pig feeding trial and their effect on serum cholesterol levels, feces $\mathrm{pH}$, and feces moisture content. International Journal of Food Microbiology, 40(1-2), 1998), 93-104.

[22]. D.I.Pereira, A.L McCartney, and G.R. Gibson, An in vitro study of the probiotic potential of a bile-salt-hydrolyzing Lactobacillus fermentum strain, and determination of its cholesterol-lowering properties. Applied. Environmental Microbiology, 69(8), 2003 47434752.

[23]. B.V. Jones, M, Begley, C. Hill, C.G. Gahan, and JR Marchesi ,Functional and comparative metagenomic analysis of bile salt hydrolase activity in the human gut microbiome. Proceedings of the National Academy of Sciences United States of America, 105(36), 2008, 13580-13585

[24]. J.Beganovic, B. Kos, A.L Pavunc, K.Uroic, P DZidara. and J. Suskovic, Proteolytic activity of probiotic strain Lactobacillus helveticus M92. Anaerobe 20, 2013,58-64.

[25]. Osaana N. Donkor, Anders Henriksson, Todor Vasiljevic, Nagendra P. Shah.2007. Proteolytic activ-ity of dairy lactic acid bacteria and probiotics as determinant of growth and in vitro angiotensin-converting enzyme inhibitory activity in fermented milk. Le Lait. 87 (1): 21-38

[26]. Sharaf, F., El-Sayed Wael, S., and Abosaif Roaa, M., (2014) . Lecithinase-producing bacteria incommercial and home-made foods: Evaluation of toxic properties and identification of potent producers,_J Taibah Univ Sci. 8 (3): 207-215. 